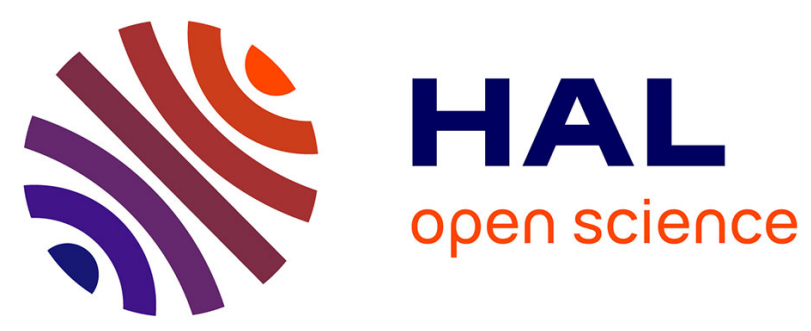

\title{
Migration of trichloroethylene in a homogeneous porous medium. 2D numerical study
}

Annelise Emonet, Michel A. Bues, Constantin Oltean, Olivier Bour, Pierre Le Thiez

\section{- To cite this version:}

Annelise Emonet, Michel A. Bues, Constantin Oltean, Olivier Bour, Pierre Le Thiez. Migration of trichloroethylene in a homogeneous porous medium. 2D numerical study. 14. International Conference on Computational Methods in water Resources, Jun 2002, Delft, Netherlands. ineris-00972370

\section{HAL Id: ineris-00972370 \\ https://hal-ineris.archives-ouvertes.fr/ineris-00972370}

Submitted on 3 Apr 2014

HAL is a multi-disciplinary open access archive for the deposit and dissemination of scientific research documents, whether they are published or not. The documents may come from teaching and research institutions in France or abroad, or from public or private research centers.
L'archive ouverte pluridisciplinaire HAL, est destinée au dépôt et à la diffusion de documents scientifiques de niveau recherche, publiés ou non, émanant des établissements d'enseignement et de recherche français ou étrangers, des laboratoires publics ou privés. 
Migration of Trichloroethylene in a homogeneous porous medium. 2D numerical study.

\author{
A. Emonet ${ }^{1}$, M.A. Buès ${ }^{1}$, C. Oltean ${ }^{1}$, O. Bour ${ }^{2}$, P. Le Thiez ${ }^{3}$ \\ (1) Laboratoire Environnement Géomécanique et Ouvrages \\ Ecole Nationale Supérieure de Géologie \\ Rue du Doyen Marcel Roubault - B.P. 40 \\ F - 54501 Vandoeuvre-lès-Nancy \\ (2) Institut National de l'Environnement Industriel et des Risques \\ Parc technologique Alata - B.P. 2 \\ $F-60550$ Verneuil-en-Halatte \\ (3) Institut Français du Pétrole \\ 1 - 4 Rue de Bois Préau \\ F - 92500 Rueil Malmaison
}

\begin{abstract}
The infiltration of hydrocarbons and chlorinated solvents in soils and groundwater represents one of the most serious risks of long-term contamination. Transport of Dense Non-Aqueous Phase Liquids (DNAPL) and especially chlorinated solvents is controlled by their physical and chemical properties. The aim of this work is to better understand the behaviour of Trichloroethylene (TCE) in a homogeneous porous medium by using both experimental data and numerical simulations. The study focuses on the influence of capillary fringe and differential water saturation on the behaviour of TCE phases. The experimental data of capillary pressure curve versus water saturation obtained for a homogeneous porous medium is used in the numerical study carried out with SIMUSCOPP package and is compared with simulations performed without taking into account capillary fringe.
\end{abstract}

\title{
1. INTRODUCTION
}

Dense Non Aqueous Phase Liquids (DNAPL) encountered in subsurface can have a variable physical and chemical behaviour depending on the type of fluid present in soils (oil, water and gas) as well as the soil matrix [1]. It can be found under different chemical species: dissolved compound, organic liquid, volatile compound or adsorbed compound. Each form represents a pollution risk for groundwater and soil. A better understanding of these mechanisms will allow us to predict the change of front propagation and help us to elaborate remediation processes.

Mass transfers between DNAPL and water, during the dissolution process, have been studied by authors during the 1990's ([2], [3], [4], [5], [6]). Dissolution processes take place in several stages. The first is the movement of a compound inside the NAPL phase towards the fluid interface. In this case, chemical transfer occurs at the interface between fluids. Diffusive processes will cause mobilisation of dissolved compounds, away from the interface. 
The maximum concentration of dissolved compound might be lower or equal to solubility but this process may be limited by different causes ([7], [3], [4]) such as: non uniform flow of aqueous and organic phases due to aquifer heterogeneities, influence of equilibrium concentration on the composition of a NAPL mixture, etc.

Mass transfers during volatilisation have also been studied ([8], [9]). Sleep and Sykes [8] showed that movement of volatile compound due to advection is influenced by density driven flow. Cho et al. [10] and Jellali et al. [11] have investigated the dissolution process of TCE vapour after water infiltration.

In our study, we focus on the influence of water saturation on mass transfers between TCE organic phase and dissolved or volatile phases during infiltration across the unsaturated zone up to reaching the saturated zone. In this study, we do not take adsorption into account. The behaviour of TCE depends on water saturation i.e.: unsaturated zone, capillary fringe or saturated zone. Thus, it is important to precisely evaluate the local water saturation of the porous medium. The determination of capillary pressure data provides us with relative permeabilities which control TCE behaviour in the capillary fringe.

Several theoretical models based on capillary pressure, water saturation and relative permeabilities will be introduced first in this paper. Subsequently, it is explained how the experimental retention curve (capillary pressure versus water saturation) was obtained in order to determine the water saturation change along the capillary fringe. In the final section, we compare SIMUSCOPP simulations implemented with and without considering capillary fringe.

\section{GOVERNING EQUATIONS FOR THE OBTAINING OF CAPILLARY PRESSURE AND RELATIVE PERMEABILITIES DATA}

Capillary pressure and relative permeabilities are important data in multiphase fluid transport in soils but are quite difficult to obtain experimentally. Therefore, several theoretical models for predicting capillary pressure and relative permeabilities have been proposed. In this study, we retain the models proposed by Van Genuchten - Mualem and Parker.

The experimental soil-water retention curve of Van Genuchten (1980) [12] yields the parameters necessary to predict relative permeabilities using Mualem's model. The general equation (1) links effective water saturation $S^{*}($ Eq. 2$)$ to pressure head $(h, h>0)$ :

$$
\begin{array}{llll}
S^{*}=\left[1+(\alpha h)^{n}\right]^{-m} & \text { (1) } & \text { and } & S^{*}=\frac{S-S_{\text {residual }}}{S_{\text {saturated }}-S_{\text {residual }}} \\
\mathrm{m}=1-1 / \mathrm{n} & \text { (3) } & \text { and } & \alpha=\frac{1}{h_{P}}\left(2^{1 / m}-1\right)^{1-m}
\end{array}
$$

where $\mathrm{n}, \mathrm{m}$ and $\alpha$ are curve shape parameters determined with the soil-water retention curve. Van Genuchten showed that $\mathrm{P}$ is the inflection point and for $\mathrm{P}$ we have also:

$$
S_{p}=\frac{1}{\left(S_{\text {saturated }}-S_{\text {residual }}\right)}\left|\frac{d S}{d(\log h)}\right|
$$

if $0<S p \leq 1$ then $m=1-\exp (-0.8 S p)$ and if $S p>1$ then $m=1-\frac{0.5755}{S p}+\frac{0.1}{S p^{2}}+\frac{0.025}{S p^{3}}$.

Then relative permeabilities for the couple water-air for a soil are given by equation (6): 


$$
k_{r w}\left(S_{w}^{*}\right)=S_{w} *^{1 / 2}\left[1-\left(1-S_{w} *^{1 / m}\right)^{m}\right]^{2} \text { with } 0<\mathrm{m}<1 \text { and Eq. } 3
$$

Equation (6) is valid for two-phase, air-water system. This can be adapted for a threephase system i.e. air, water and NAPL [13]. In such a system, NAPL is supposed to have an intermediate wettability between air and water. We assume in this paper that this formulation is applicable for all NAPL. For each couple the two-phase formulation for the different fluids in a three-phase system yields:

$$
\begin{aligned}
& S_{j}^{* i j}=\left[1+\left(\alpha_{i j} h_{i j}\right)^{n}\right]^{-m} \text { if } h_{i j}>0 \text { and } S_{j}^{* i j}=1 \text { if } h_{i j} \leq 0 \text { for } \mathrm{i}, \mathrm{j}=\mathrm{a}, \mathrm{o}, \mathrm{w} \text { with } \mathrm{i} \neq \mathrm{j} \\
& S_{t}^{* a o w}=\left[1+\left(\alpha_{a o} h_{a o}\right)^{n}\right]^{-m} \text { if } h_{a o}>0 \text { and } S_{t}^{* a o w}=1 \text { if } h_{a o} \leq 0
\end{aligned}
$$

where the total liquid saturation in a three phase liquid system is defined by $\mathrm{S}^{*}$ and $S_{j}^{* i j}$ is expressed as:

$$
S_{j}^{* i j}=\frac{S_{j}^{i j}-S_{\text {residual }}}{1-S_{\text {residual }}} \quad \text { (9) and } \quad S_{t}^{* a w^{a}}=\frac{S_{t}^{\text {aow }}-S_{\text {residual }}}{1-S_{\text {residual }}}
$$

Other studies have shown that NAPL relative permeabilities in a three-phase system depend mainly on gas and water saturation. According to Parker [13], if the air-water relative permeabilities are given by equation (6), then, for the other fluids, these equations can be expressed as:

$$
\begin{aligned}
& k_{r a}=C S_{a} *^{1 / 2}\left(1-S_{t} *^{1 / m}\right)^{2 m} \text { with } \mathrm{C} \text { a gas slippage correction coefficient } \\
& \left.k_{r o}=\left(S_{t}^{*}-S_{w}^{*}\right)^{1 / 2}\left\{1-S_{w}^{*^{1 / m}}\right]^{n}-\left[1-S_{t}^{*^{1 / m}}\right]^{m}\right\}
\end{aligned}
$$

These models enable us to determine relative permeabilities for the three phases from capillary pressure and water saturation data. The data obtained experimentally and processed by this method is implemented in SIMUSCOPP. Its influence will be shown in paragraph 4.

\section{DETERMINING THE RETENTION CURVE}

The porous medium used in the whole experimental study is a natural sand from the Moselle river, eastern France. It is mainly composed of quartz with a small proportion of feldspar. Its main characteristics are as follows: effective porosity of 0.38 ; hydraulic conductivity close to $2.10^{-4} \mathrm{~m} / \mathrm{s}$ and mean grain-size between 0.4 and $0.6 \mathrm{~mm}$.

The experimental apparatus (Figure 1) used for the determination of the retention curve consisted of a stack of 8 plexiglas cylinders $(9 \mathrm{~cm}$ in diameter and $7 \mathrm{~cm}$ in height). The assembled column height is about $55 \mathrm{~cm}$. It is first filled with water then sand is progressively added in $400 \mathrm{~g}$ portions. The column is struck several times with a hammer in order to optimise grain sand distribution and to avoid compressive effects. Tensiometer probes are attached on the cylinder; one end is buried the porous medium and the other end is linked to a pressure gauge. The change in pressure inside the porous medium during the experiment is recorded. Three tests have been conducted in the same experimental conditions in order to test the retention curve. The results of these tests are presented in Figure 2. 


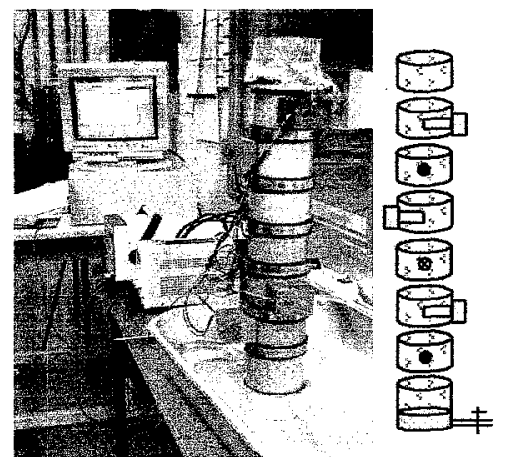

Figure 1: Experimental set-up.

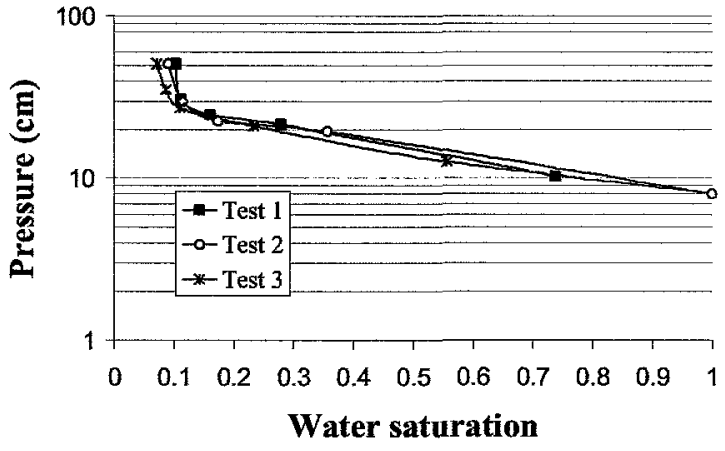

Figure 2: Experimental results of the water retention curve.

Experimental curves are relatively similar for all tests and yield Van Genuchten model parameters i.e. $\alpha$ and $\mathrm{n}$ listed in Table 1 :

Table 1

\begin{tabular}{cccccc}
\hline Test & S max & S min & m & $\mathbf{n}$ & $\boldsymbol{\alpha}\left[\mathbf{m}^{-1}\right]$ \\
\hline Test 1 & 1 & 0.1037 & 0.658 & 2.92 & 0.1032 \\
Test 2 & 1 & 0.0905 & 0.684 & 3.16 & 0.0919 \\
Test 3 & 1 & 0.0712 & 0.745 & 3.92 & 0.0930 \\
Mean & 1 & 0.0885 & 0.696 & 3.33 & 0.0960 \\
\hline
\end{tabular}

The variation of each parameter is between $15 \%$ to $18 \%$ for Smin and $n$ and around $6.5 \%$ for $m$ and $\alpha$. Values obtained for test 2 are intermediate compared with test 1 and test 3 , so we may consider that it is representative of the other tests.

These parameters enable us to estimate the relative permeabilities for each two-phase fluidcouple in a three-phase system. In SIMUSCOPP, hysteresis is not considered. Therefore, we will focus our attention on the drainage curve and not on that of imbibition. These experimental and analytical values have been implemented in SIMUSCOPP and compared to a simulation which does not consider capillary pressure.

\section{SIMULATION OF TCE MIGRATION WITH SIMUSCOPP}

SIMUSCOPP is a numerical modelling software package developed by the French Institute of Petroleum (IFP). It solves a set of coupled transport equations for fluid velocities, pressure and concentration of chemical species in multiphase flow. Several chemical species can be found in one, two or three fluid phases. The governing equations are based on mass balance and momentum equations, except that those of Darcy are used in place of those of NavierStokes. Two cases can be considered, whether or not mass transfer between phases and fluids is taken into account. The geometry considered in these simulations uses regular radial coordinates.

The set-up simulated represents a column, $20 \mathrm{~cm}$ in internal diameter and $100 \mathrm{~cm}$ in length. It is divided into 400 elements of $0.5 \mathrm{~cm}$ in radius and $1 \mathrm{~cm}$ in depth. We consider the column as a cylinder. Numerical simulations are applied to the angular width of each cell. Graphic representations are illustrated using a vertical section of the column where we 


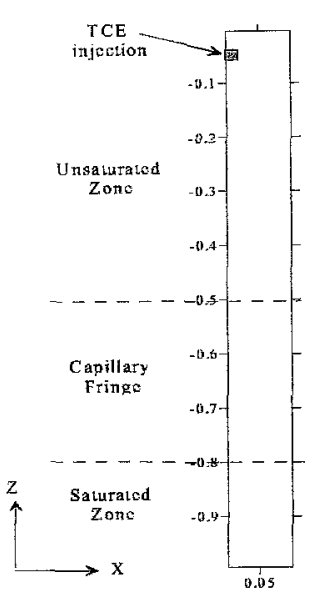

consider only a radius. In this way, the injection of TCE which takes place in the centre of the column is represented in one side of the column. The characteristics of the porous medium are those indicated in paragraph 3. In this case, SIMUSCOPP is used in a multiphase structure; therefore relative permeabilities and capillary pressure data for each couple of fluids are required.

For each simulation, the unsaturated zone is situated at depths between 0 and $0.5 \mathrm{~m}$, the capillary fringe between 0.5 and $0.8 \mathrm{~m}$ and the saturated zone between 0.8 and $1 \mathrm{~m} .100 \mathrm{~mL}$ of TCE are injected over 2 hours in the upper part of the model. The injection zone $(1.5 * 1$ $\mathrm{cm}^{2}$, i.e. 3 cells in direction $\mathrm{X}$ and 1 cell in direction $\mathrm{Z}$ ) is situated $5 \mathrm{~cm}$ below the ground surface, in order to avoid volatilisation of TCE. The different species of TCE (organic phase, volatile and dissolved) are illustrated in Figure 4.

Five simulations experiments have been conducted: one without the implementation of capillary pressure data (test 0 ) and the others with capillary pressure and relative permeabilities obtained experimentally (test 1 to 3 ), as described in paragraph 2 and 3 . The influence of each experimental capillary pressure - water saturation curve on water saturation distribution along the column is illustrated in Figure 3.

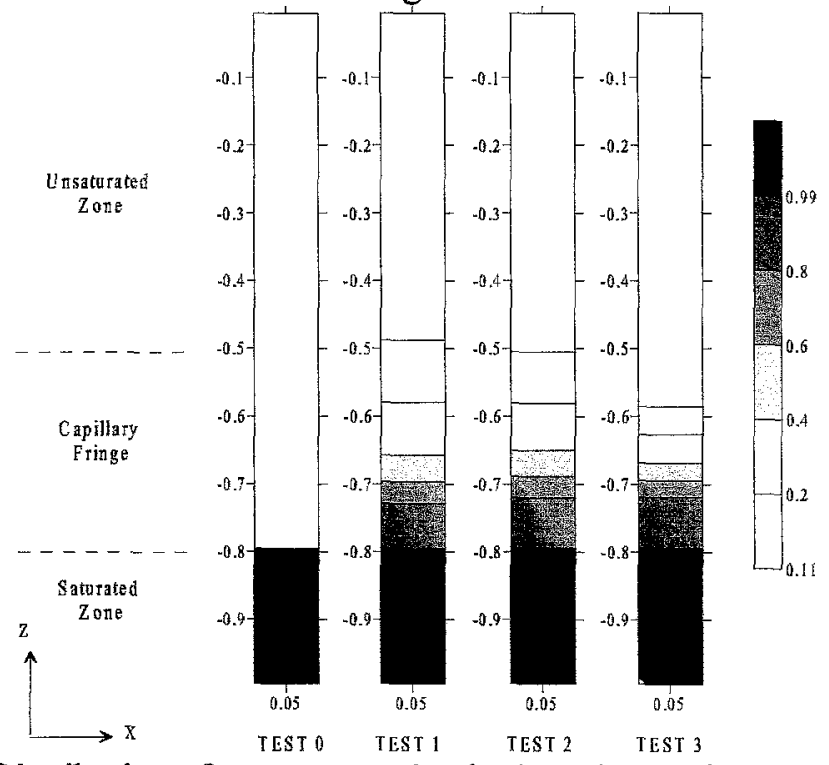

Figure 3: Distribution of water saturation in the column after simulation with SIMUSCOPP.

In a simulation where capillary pressure is ignored (test 0 ), a distinct separation surface is obtained between the two zones: saturated and unsaturated, without any gradation in water saturation. The capillary fringe is absent. On the other hand, the use of the experimental curves induces the appearance of a capillary fringe whose height varies between 20 (test 3 ) and $30 \mathrm{~cm}$ (test 1). Moreover, as numerical simulations give similar results for test 1 and test 2 , we can consider one of these tests (e.g. test 2 ) as the most representative. The influence of the experimental capillary pressure - water saturation curve on the behaviour of different 
species of TCE will be discussed for test 2 . Numerical results of this simulation are illustrated and compared with those of test 0 , in Figure 4.

In Figure $4 a$, one can observe the evolution of oil saturation in time for test 0 (dark) and test 2 (light). For test 0 , TCE penetrates rapidly into the porous medium and spreads through the lower part of the column (saturated zone). The migration is primarily vertical. Conversely, TCE in test 2 crosses the unsaturated zone more slowly with a more extensive lateral extension. When TCE encounters the capillary fringe it slows down and accumulates in the upper part of the saturated zone.

In Figure $4 \mathrm{~b}$ and Figure $4 \mathrm{c}$, the migration of volatile TCE and dissolved TCE is illustrated. These chemical species are represented according to its maximum molar fraction for TCE vapour (equal to 0.077 ) and maximum concentration in water for dissolved TCE (equal to TCE solubility, i.e. $1100 \mathrm{mg} / \mathrm{L}$ ).

Concerning the migration of TCE vapours, numerical simulations show markedly different behaviour between test 0 and test 2 . For the first one, we observe that during the first hour, TCE vapours are located at the place of the TCE path, towards the centre of the column. Vapours then begin to spread laterally and after 3 hours they occupy almost the whole of the unsaturated zone. For test 2 , in the same time interval, TCE vapours follow the slow migration of TCE in the column. Lateral extension is more extensive than in test 0 and vertical migration is slower. After 2 hours, the unsaturated zone is almost completely saturated with TCE vapours.

Figure $4 \mathrm{c}$ shows the evolution of dissolved TCE. For test 0 , dissolved TCE is only located in the saturated zone during the first hour. After 2 hours of simulation, dissolved TCE is also found in the unsaturated zone. This is probably due to solubilization of vapours in contact with irreducible water in the unsaturated zone. In the saturated zone, dissolved TCE is present at the bottom of the column. For test 2, dissolved TCE, as for TCE vapours, follows the migration of TCE organic phase. The lateral migration is significant and the vertical migration stops at the upper part of the saturated zone.

\section{CONCLUSION}

In this study, we have shown the experimental results of determining capillary pressure water saturation curve for a porous medium. For a homogeneous porous medium, similar experimental curves of capillary pressure versus water saturation have been obtained. In a numerical model, this experimental data and estimated parameters enable us to numerically study the migration of TCE with or without taking the capillary fringe into account. The behaviour of TCE in these two cases is markedly different. The presence of a capillary fringe causes a slowdown of TCE migration but a more extensive lateral extension and an increase in the velocity of contamination by TCE vapours and dissolved TCE in the unsaturated zone.

These numerical results will be compared with new experimental results concerning TCE migration in a $2 \mathrm{D}$ column. 


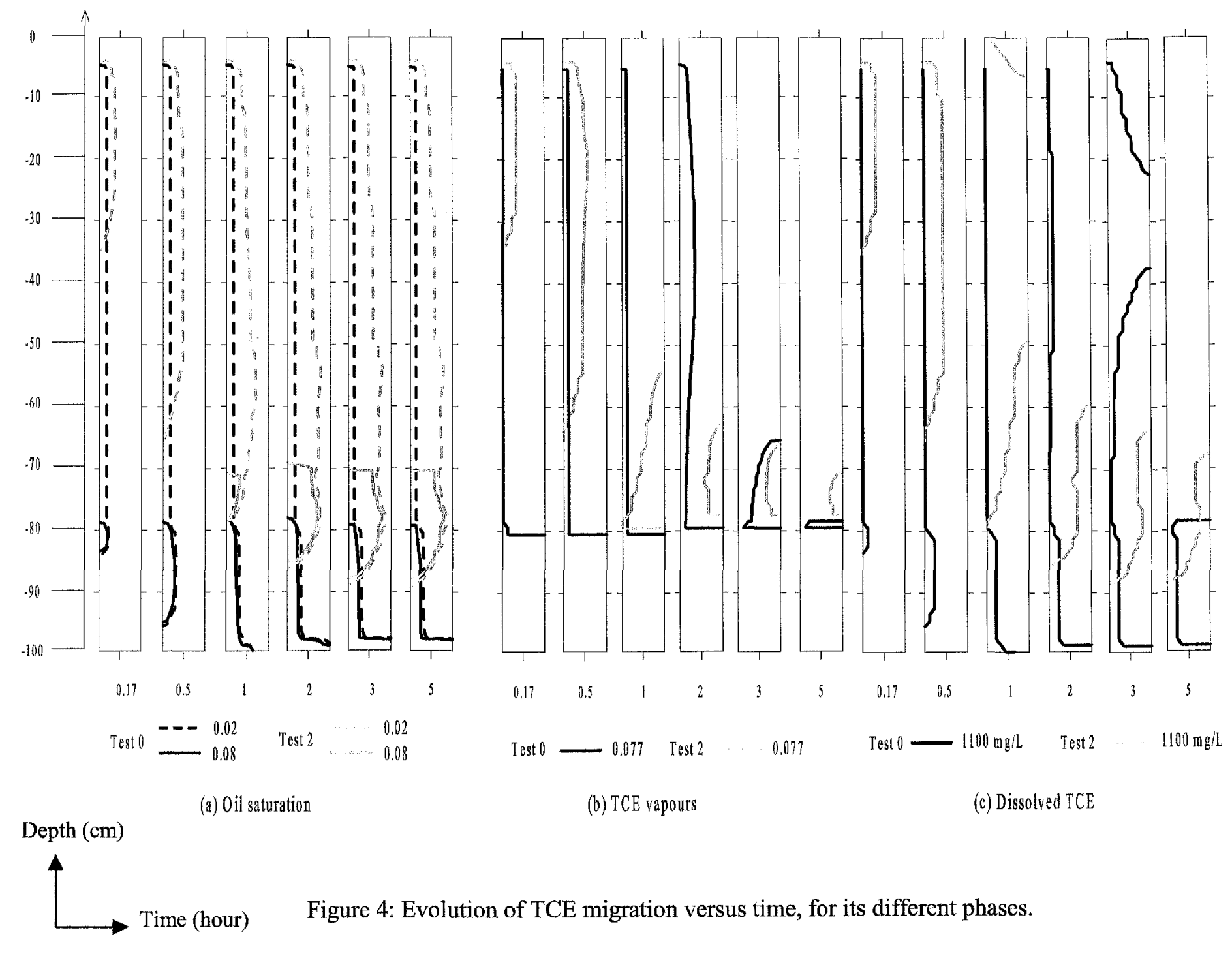




\section{REFERENCES}

[1] PANKOW J.F. and CHERRY J.A. - Dense chlorinated solvents and other DNAPLs in groundwater: History, Behavior, and Remediation. Waterloo Press, Ontario, Canada, 260 p, 1996.

[2] MILLER C.T., POIRIER-McNEIL M.M. and MAYER A.S. - Dissolution of trapped nonaqueous phase liquids: mass transfer characteristics. Water Resources Research, vol 26, $\mathrm{N}^{\circ} 11, \mathrm{p} 2783-2796,1990$.

[3] POWERS S.E., LOUREIRO C.O., ABRIOLA L.M. and WEBER W.J. - Theoretical study of the significance of non-equilibrium dissolution of non-aqueous phase liquids in subsurface systems. Water Resources Research, vol 27, N²4, p 463-477, 1991.

[4] POWERS S.E., ABRIOLA L.M and WEBER W.J. - An experimental investigation of non-aqueous phase liquid dissolution in saturated subsurface systems : steady state mass transfer rates. Water Resources Research, vol. 28, $\mathrm{N}^{\circ} 10, \mathrm{p}$ 2691-2705, 1992.

[5] GELLER J.T. and HUNT J.R. - Mass transfer from non-aqueous phase organic liquids in water-saturated porous media. Water Resources Research, vol 29, №4, p 833-845, 1993.

[6] POWERS S.E., ABRIOLA L.M and WEBER W.J. - An experimental investigation of non-aqueous phase liquid dissolution in saturated subsurface systems : transient mass transfer rates. Water Resources Research, vol. 30, No2, p 321-332, 1994.

[7] ABRIOLA L.M. - Modeling multiphase migration of organic chemicals in groundwater systems. A review and assessment. Environmental Health Perspectives, vol 83, p117-143, 1989.

[8] SLEEP B.E. and SYKES J.F. - Modelling the transport of volatile organics in variably saturated media. Water Resources Research, vol 25, No $1, \mathrm{p} 81-92,1989$.

[9] GRIFFOL J. and COHEN Y. - Contaminant migration in the unsaturated soil zone: the effect of rainfall and evapotranspiration. Journal of Contaminant Hydrology, vol 23, p 185$211,1996$.

[10] CHO H.J., JAFFE P.R. and SMITH J.A. - Simulating the volatilisation of solvents in unsaturated soils during laboratory and field infiltration experiments. Water Resources Research, vol 29, N¹0, p 3329-3342, 1993.

[11] JELLALI S., MUNTZER P, RAZAKARISOA O. and SCHÄFER G. - Large scale experiment on transport of Trichloroethylene in a controlled aquifer. Transport in Porous Media. Vol 44, p 145-163, 2001.

[12] VAN GENUCHTEN M. Th. - A closed-form equation for predicting the hydraulic conductivity of unsaturated soils. Soil Sci. Soc. Am. J., vol 44, p 892-898,1980.

[13] PARKER J.C., LENHARD R.J. and KUPPUSAMY T. - A parametric model for constitutive properties governing multiphase flow in porous media. Water Resources Research, Vol 23, №4, p 618-624, 1987. 